\title{
The importance of the malleable implant salvage technique (MIST) in modern prosthetic urology
}

\author{
Alex Tatem ${ }^{1}$, Jason R. Kovac ${ }^{2}$ \\ ${ }^{1}$ Department of Urology, Indiana University, Indianapolis, Indiana, USA; ${ }^{2}$ Men's Health Center, Indianapolis, Indiana, USA \\ Correspondence to: Dr. Jason R. Kovac, MD, PhD, FACS, FRCSC. Men's Health Center, 8240 Naab Road, Suite 220, Indianapolis, Indiana 46260, \\ USA. Email: jkovac@urologyin.com. \\ Comment on: Lao M, Graydon RJ, Bieniek JM. Salvage penile prosthetic surgery utilizing temporary malleable implants. Transl Androl Urol \\ 2017;6:S806-12.
}

Submitted Nov 13, 2017. Accepted for publication Nov 13, 2017.

doi: $10.21037 /$ tau.2017.11.15

View this article at: http://dx.doi.org/10.21037/tau.2017.11.15

Management of an infected penile prosthesis presents a challenging problem that is thankfully, a rare occurrence. For many years the standard of care was complete removal of the device followed by convalescence and a prolonged course of antibiotics. Unfortunately, the resulting corporal fibrosis made subsequent device placement much more challenging. This often necessitated insertion of a smaller implant with a higher risk of repeat infection and subsequent perforation.

Prosthetic urology was then revolutionized in 1996 when Dr. John J. Mulcahy published a landmark paper detailing the salvage procedure that now bears his name (1). This was the first time that a salvage surgery was presented as a viable option to an infected prosthesis. A follow-up series found the procedure had a greater than $80 \%$ success rate (2). This approach, which replaced an infected device with a new one, eliminated the corporal fibrosis associated with scarring and obliteration of the corporal space, preserved penile length and provided patients with a durable resolution in a single surgery.

Unfortunately, not every patient is a candidate for salvage. A large percentage of men who present with infection will do so with complications involving the scrotum (3). This often precludes salvage with a 3-piece inflatable prosthesis as scrotal tissues are frequently compromised. Consequently, the concept of the malleable implant salvage technique (MIST) has gained popularity $(4,5)$. Indeed, we have adopted it at our own institution with great success.

It is important to emphasize that, as with the original
Mulcahy salvage protocol $(1,2)$, pre-operative admission for wound culture and treatment with broad-spectrum antibiotics is essential. This allows for the adequate treatment of any residual soft tissue infections that cannot be addressed with the intra-operative washout. Pre-admission also allows the surgery to be performed in a planned and controlled fashion. Infectious disease physicians and anesthesia, along with surgeons familiar with the salvage protocols, could be notified and an expedient surgery appropriately planned.

Although both Boston Scientific (American Medical Systems) and Coloplast offer malleable prostheses with variable cylinder lengths and girths, it is important not to upsize patients in either dimension at time of salvage. This could increase the risk for perforation or other complications given the already compromised tissues.

Another notable aspect of prior research on the MIST is that a large percentage of patients choose not to pursue conversion to a 3 -piece device (5). Indeed, even removed from the salvage setting, malleable implants have a very high level of patient satisfaction $(\sim 75 \%)(6,7)$. Given that many patients undergoing salvage are older, and less functional than they were at the time of initial device placement, eliminating another surgical procedure is potentially an enormous benefit.

The MIST represents an important evolution of modern prosthetic urology. The technique allows for preservation of sexual function in a vulnerable patient population with a success rate greater than $90 \%$. Furthermore, it allows for salvage in patients who previously may not have been 
considered candidates (4) and potentially obviates the need for future surgical interventions.

\section{Acknowledgements}

None.

\section{Footnote}

Conflicts of Interest: The authors have no conflicts of interest to declare.

\section{References}

1. Brant MD, Ludlow JK, Mulcahy JJ. The prosthesis salvage operation: immediate replacement of the infected penile prosthesis. J Urol 1996;155:155-7.

2. Mulcahy JJ. Long-term experience with salvage of infected penile implants. J Urol 2000;163:481-2.

Cite this article as: Tatem A, Kovac JR. The importance of the malleable implant salvage technique (MIST) in modern prosthetic urology. Transl Androl Urol 2017;6(Suppl 5):S813S814. doi: $10.21037 /$ tau.2017.11.15
3. Lao M, Graydon RJ, Bieniek JM. Salvage penile prosthetic surgery utilizing temporary malleable implants. Transl Androl Urol 2017;6:S806-12.

4. Köhler TS, Modder JK, Dupree JM, et al. Malleable implant substitution for the management of penile prosthesis pump erosion: a pilot study. J Sex Med 2009;6:1474-8.

5. Gross MS, Phillips EA, Balen A, et al. The Malleable Implant Salvage Technique: Infection Outcomes after Mulcahy Salvage Procedure and Replacement of Infected Inflatable Penile Prosthesis with Malleable Prosthesis. J Urol 2016;195:694-7.

6. Bozkurt IH, Arslan B, Yonguc T, et al. Patient and partner outcome of inflatable and semi-rigid penile prosthesis in a single institution. Int Braz J Urol 2015;41:535-41.

7. Casabé AR, Sarotto N, Gutierrez C, et al. Satisfaction assessment with malleable prosthetic implant of Spectra (AMS) and Genesis (Coloplast) models. Int J Impot Res 2016;28:228-33. 